\title{
Enhanced visible-light-driven photocatalytic activities of 0D/1D heterojunction carbon quantum dot modified CdS nanowires
}

\author{
Zhiwei Chen a,b, Chang Feng b,*, Weibing Li a,b,\#, Zhiyong Sun b, Jian Hou b, Xiangbo Li b, Likun Xu ${ }^{\text {, }}$ \\ Mingxian Sun ${ }^{b}$, Yuyu Bu c,\$ \\ a School of Environment and Safety Engineering, Qingdao University of Science and Technology, Qingdao 266042, Shandong, China \\ b State Key Laboratory for Marine Corrosion and Protection, Luoyang Ship Material Research Institute, Qingdao 266237, Shandong, China \\ ' Key Laboratory of Wide Band-Gap Semiconductor Materials and Devices, School of Microelectronics, Xidian University, Xi'an 710071, Shaanxi, China
}

\section{A R T I C L E I N F O}

Article history:

Received 19 November 2017

Accepted 9 December 2017

Published 5 April 2018

\section{Keywords:}

Semiconductor photocatalysis

Heterojunction

CdS nanowire

Carbon quantum dot

Water splitting

\begin{abstract}
A B S T R A C T
Zero-dimensional carbon dots (OD C-dots) and one-dimensional sulfide cadmium nanowires (1D CdS NWs) were prepared by microwave and solvothermal methods, respectively. A series of heterogeneous photocatalysts that consisted of 1D CdS NWs that were modified with 0D C-dots (C-dots/CdS NWs) were synthesized using chemical deposition methods. The mass fraction of C-dots to CdS NWs in these photocatalysts was varied. The photocatalysts were characterized using X-ray diffraction, scanning electron microscopy, transmission electron microscopy, X-ray photoelectron spectroscopy, and ultraviolet-visible spectroscopy. Their photocatalytic performance for the spitting of water and the degradation of rhodamine $\mathrm{B}(\mathrm{RhB})$ under visible light irradiation were investigated. The photocatalytic performance of the C-dots/CdS NWs was enhanced when compared with that of the pure CdS NWs, with the $0.4 \%$ C-dots/CdS NWs exhibiting the highest photocatalytic activity for the splitting of water and the degradation of RhB. The enhanced photocatalytic activity was attributed to a higher carrier density because of the heterojunction between the C-dots and CdS NWs. This heterojunction improved the electronic transmission capacity and promoted efficient separation of photogenerated electrons and holes.
\end{abstract}

(C) 2018, Dalian Institute of Chemical Physics, Chinese Academy of Sciences. Published by Elsevier B.V. All rights reserved.

\section{Introduction}

Energy production and environmental pollution have become increasingly important issues for social and economic development. Photocatalytic technologies show great promise to help solve these problems as they can convert solar energy into chemical energy efficiently [1,2]. Since the discovery of water splitting using $\mathrm{TiO}_{2}$ by Fujishima et al. [3] in 1972, photocatalytic technology has attracted significant attention [4-6].
However, $\mathrm{TiO}_{2}$ is a wide bandgap semiconductor $(\sim 3.2 \mathrm{eV})$ and as such can only be excited by ultraviolet light. As ultraviolet energy only accounts for $4 \%-5 \%$ of the solar spectrum, while visible light accounts for the majority of total solar radiation energy, the use of $\mathrm{TiO}_{2}$ in these applications is limited. Therefore, the development of semiconductor materials that allow photocatalysis when irradiated with visible light is of great importance.

Cadmium sulfide (CdS) is of particular interest as it is a nar-

\footnotetext{
* Corresponding author. Tel: +86-532-68725125; Fax: +86-532-68725100; E-mail: fchang1988@126.com

\# Corresponding author. Tel/Fax: +86-532-84022617; E-mail: lwbing@qust.edu.cn

\$Corresponding author. Tel/Fax: +86-29-88202505; E-mail: buyuyuqust@163.com

This work was financially supported by the Research Fund of State Key Laboratory for Marine Corrosion and Protection of Luoyang Ship Material Research Institute (LSMRI) (KF160413), and the National Natural Science Foundation of China $(21301161,41376126)$.

DOI: 10.1016/S1872-2067(17)62972-3 | http://www.sciencedirect.com/science/journal/18722067 | Chin. J. Catal., Vol. 39, No. 4, April 2018
} 
row bandgap semiconductor $(\sim 2.4 \mathrm{eV})$ that responds to visible light, has a relatively simple chemical structure and exhibits high photocatalytic performance [7-10]. However, the photogenerated electrons and holes undergo fast recombination, which limits the practical use of CdS. Improving the separation efficiency of photogenerated electron-hole pairs is key to enhancing the photocatalytic activity of CdS. This problem can be solved by controlling morphology [11] and by surface modification of CdS $[12,13]$. The large specific surface area of 1D CdS NWs and their unique topographic structure favors the transfer of the electrons from the bulk to the surface, which is advantageous for photocatalytic reactions [14]. Surface modification primarily relies on the fabrication of a heterojunction structure using CdS with other materials, such as $\mathrm{TiO}_{2}[15,16], \mathrm{ZnO}$ $[17,18], \mathrm{MoS}_{2}$ [19] and precious metals (Au [20], Ag [21]). This method improves the photocatalytic performance of CdS. However, these materials require complex and costly preparation methods. Therefore, developing new materials using simple preparation methods for low cost is critical.

Carbonaceous materials, including graphene, carbon nanotubes and carbon quantum dots (CQDs) have proven effective when coupled with photocatalysts at inhibiting the recombination of photogenerated electron-hole pairs because of their unique physical and optical properties [22-25]. Among these carbon-based materials, 0D C-dots are a relatively new carbon nanomaterial with a size below $10 \mathrm{~nm}$, and were first obtained by electrostripping carbon nanotubes in 2004 [26]. As this material is low cost and non-toxic, it has been used for biological imaging, devices, photoelectric chemistry, supercapacitors and photocatalysis $[27,28]$.

The heterojunction formed when C-dots are loaded onto the surface of a semiconductor material can greatly improve its photocatalytic performance and stability [25]. In addition to the up-conversion function of the carbon-based material in these heterojunction systems, C-dots can also replace precious metals as the center of photo-induced electron, which effectively separates the photoinduced carrier [29-32] and results in improved photocatalytic performance. Xia et al. [33] successfully prepared carbon quantum dots/BiOX $(\mathrm{X}=\mathrm{Br}, \mathrm{Cl})$ hybrid nanosheets to investigate their photocatalytic performance under visible light irradiation. These systems exhibited highly efficient separation of the photogenerated electron-holes pairs and only a small resistance induced by the CQDs was observed using electrochemical impedance spectroscopy (EIS). Huang et al. [34] prepared environmentally friendly $\mathrm{CQDs} / \mathrm{ZnFe}_{2} \mathrm{O}_{4}$ photocatalysts and they reported that the CQDs acted as an electron reservoir and transporter as well as a powerful energy-transfer component in the photocatalysis of $\mathrm{CQDs} / \mathrm{ZnFe}_{2} \mathrm{O}_{4}$.

In this work, 0D C-dots and 1D CdS NWs were synthesized using microwave and solvothermal methods, respectively. C-dots/CdS NWs heterojunction photocatalysts were then prepared using a simple chemical deposition method. The C-dots/CdS NWs exhibited improved photocatalytic degradation of $\mathrm{RhB}$ and hydrogen production during the splitting of water when compared with pure CdS NWs. The mechanisms that caused this enhanced photocatalytic performance were examined.

\section{Experimental}

\subsection{Preparation of OD C-dots solution and $1 D C d S N W S$}

0D C-dots were prepared using a simple microwave method. In a typical synthesis, glucose $(0.2 \mathrm{~g})$ was dispersed in distilled water $(10 \mathrm{~mL})$ and subsequently treated in a microwave oven for $10 \mathrm{~min}$.

In a typical synthesis of $1 \mathrm{D} \mathrm{CdS} \mathrm{NWs}, \mathrm{Cd}\left(\mathrm{NO}_{3}\right)_{2} \cdot 4 \mathrm{H}_{2} \mathrm{O}(12.5$ $\mathrm{mmol}$ ) and thiourea (37.5 $\mathrm{mmol})$ were dispersed in ethylenediamine $(60 \mathrm{~mL})$. After mixing thoroughly using ultrasound, the mixture was transferred into a Teflon-lined autoclave $(100 \mathrm{~mL})$ and heated at $160{ }^{\circ} \mathrm{C}$ for $20 \mathrm{~h}$. After centrifugation, the centrifugate was washed three times with deionized water and ethanol and then dried at $60^{\circ} \mathrm{C}$ overnight.

\subsection{Preparation of $0 D / 1 D C$-dots/CdS NWS}

C-dots/CdS NWs were prepared using a simple chemical deposition method. In a typical synthesis, a measured amount of 1D CdS NWs was dispersed in distilled water (50 mL) and treated using ultrasonication for $10 \mathrm{~min}$. Subsequently, the C-dot solution was added dropwise into the CdS solution and stirred for $4 \mathrm{~h}$. The amount of solution added was varied to give weight ratios of $0.2 \%, 0.4 \%, 0.6 \%$, and $0.8 \%$ of the $0 \mathrm{D}$ C-dots solution. The mixtures were centrifuged at $8000 \mathrm{r} / \mathrm{min}$, and the resulting products were dried in an oven at $60{ }^{\circ} \mathrm{C}$ for $12 \mathrm{~h}$. The final products are referred to as $0.2 \% \mathrm{C}$-dots/CdS NWs, $0.4 \%$ C-dots/CdS NWs, $0.6 \%$ C-dots/CdS NWs, and $0.8 \%$ C-dots/CdS NWs.

\subsection{Characterization}

X-ray diffraction (XRD; D/MAX-2500/PC; Rigaku Co., Tokyo, Japan) was used to identify the crystalline structures of the samples. The micro-morphology of as-prepared pure CdS NWs and C-dots/CdS NWs were observed using field emission scanning electron microscopy (FE-SEM, Ultra 55, Zeiss, Germany). The surface microstructure and interfaces of the C-dots/CdS NWs were observed using high-resolution transmission electron microscopy (HRTEM; Tecnai G2 F20, FEI Company, USA). The elementary composition and bonding information of the materials were analyzed using X-ray photoelectron spectroscopy (XPS; Axis Ultra, Kratos Analytical Ltd., England). A UV-visible diffuse reflectance spectrophotometer (UV-vis DRS; U-41000, HITACHI, Tokyo, Japan) was used to determine the optical absorption properties of the samples. The photoluminescence of the as prepared materials were characterized using a fluorescence spectrometer (PL; Fluoro Max-4, HORIBA Jobin Yvon, France).

\subsection{Photocatalytic performance and free radical capture testing}

Testing the degradation of the dye involved adding the photocatalyst $(0.05 \mathrm{~g}$ ) into a solution of rhodamine B (RhB; 100 $\mathrm{mL}, 10 \mathrm{mg} / \mathrm{L}$ ). Before illumination, the mixture was stirred for 
$30 \mathrm{~min}$ in the absence of light. The mixture was illuminated with visible light using a 300-W Xe lamp (PLS-SXE300, Beijing Changtuo Co., Ltd., China). This was achieved using a 420-nm cut-off filter to remove the ultraviolet light. The photo density was kept at $250 \mathrm{~mW} / \mathrm{cm}^{2}$ and the temperature of the dye solution was maintained at $25^{\circ} \mathrm{C}$ using a condensate water system.

Isopropyl alcohol (IPA) and $p$-benzoquinone (BQ) were added as traps for hydroxyl radicals $(\cdot \mathrm{OH})$ and superoxide radicals $\left(\cdot \mathrm{O}_{2}^{-}\right)$, respectively. The trapping agents were added at a concentration of $5 \mathrm{mmol}$. Aside from the presence of the trapping agents, the reaction conditions were kept consistent with the photocatalytic degradation of RhB without the trapping agents.

The photocatalytic splitting of water involved dispersing the photocatalyst power $(0.01 \mathrm{~g})$ with mechanical stirring in 100 $\mathrm{mL}$ of water containing the electron donors sodium sulfide $\left(\mathrm{Na}_{2} \mathrm{~S}, 0.35 \mathrm{~mol} / \mathrm{L}\right)$ and sodium sulfite $\left(\mathrm{Na}_{2} \mathrm{SO}_{3}, 0.25 \mathrm{~mol} / \mathrm{L}\right)$. Before illumination, the pressure within the photoreaction system was lowered until the pressure gage was stable. The mixture was illuminated with visible light using a 150-W Xe lamp (PLS-SXE300, Beijing Changtuo Co., Ltd., China). This was achieved using a 420-nm cut-off filter to remove the ultraviolet light. The photo density was kept at $250 \mathrm{~mW} / \mathrm{cm}^{2}$ and the temperature of the dye solution was maintained at $25^{\circ} \mathrm{C}$ using a condensate water system.

\subsection{Fabrication of photoelectrodes and characterization of the photoelectrochemical performance}

Sample electrodes were prepared by spot coating. In brief, the photocatalyst $(20 \mathrm{mg}$ ) was dispersed in a mixture of Nafion $(4 \mu \mathrm{L})$, water $(276 \mu \mathrm{L})$ and isopropyl alcohol $(20 \mu \mathrm{L})$. The mixture was stirred for $30 \mathrm{~min}$ and coated onto FTO conductive glass $(1 \mathrm{~cm} \times 1 \mathrm{~cm})$ by spot coating, with the resulting thin films being annealed at $350{ }^{\circ} \mathrm{C}$ for $0.5 \mathrm{~h}$ to improve adhesion of the photocatalyst powder to the FTO conductive glass. The photoelectrochemical performance was examined by measuring current density-time curves (i-t curve) and EIS. A three-electrode system was used to measure the photoelectrochemical (PEC) performance. The photoelectrodes, a large piece of platinum, and a $\mathrm{Ag} / \mathrm{AgCl}$ (saturated $\mathrm{KCl}$ ) electrode were used as the working, counter, and reference electrodes, respectively. All measurements were performed in $\mathrm{Na}_{2} \mathrm{SO}_{4}$ electrolyte $(0.1$ mol/L) using a PARSTAT 4000 electrochemical system (Princeton Ltd., USA). The photocurrent density-time (i-t) curves were measured at a bias potential of $0 \mathrm{~V}$ (vs. Ag/AgCl), and the photocurrent density was maintained at $100 \mathrm{~mW} / \mathrm{cm}^{2}$. The EIS was performed at a bias potential of $0 \mathrm{~V}$ (vs. OCP) in a frequency range of $10^{5}-10^{-1} \mathrm{~Hz}$.

\section{Results and discussion}

XRD patterns of the samples are shown in Fig. 1. The patterns of CdS NWs were characteristic of a hexagonal wurtzite structure (JCPDS No. 41-1049). The XRD peaks at $24.8^{\circ}, 26.5^{\circ}$, $28.2^{\circ}, 36.6^{\circ}, 43.7^{\circ}, 47.8^{\circ}, 50.9^{\circ}, 51.8^{\circ}, 52.8^{\circ}, 58.3^{\circ}, 66.8^{\circ}, 69.3^{\circ}$, $70.9^{\circ}$ and $75.5^{\circ}$ corresponded to the (100), (002), (101), (102),

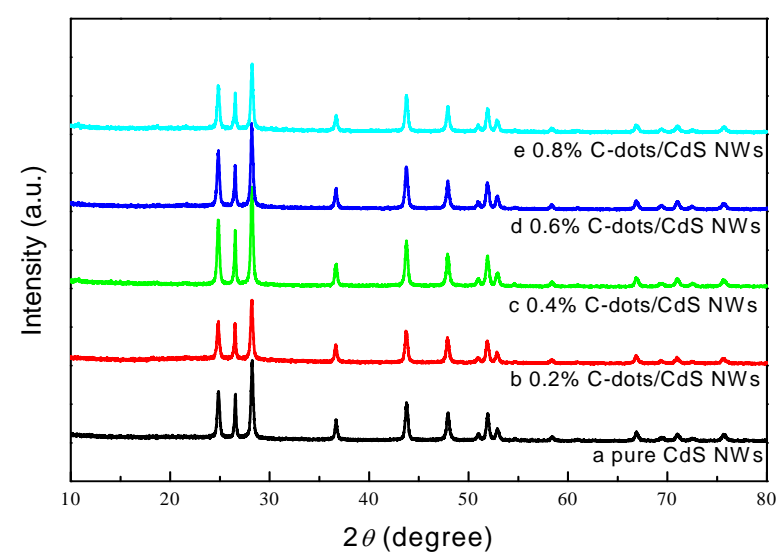

Fig. 1. XRD patterns of the pure CdS NWs and the C-dots/CdS NWs.

(110), (103), (200), (112), (201), (202), (203), (210), (211) and (105) planes of CdS, respectively. Increasing mass fractions of the C-dots did not change the XRD peaks, which indicated that their introduction did not affect the crystal structure of the CdS. The characteristic diffraction peaks of the C-dots were not observed in the C-dots/CdS NWs because of the low quantities and more scatter of C-dots. Additionally, the XRD patterns of the C-dots/CdS NWs samples did not contain any other diffraction peaks, which indicated that the samples did not contain impurities.

SEM images of pure CdS NWs and $0.4 \%$ C-dots/CdS NWs are shown in Fig. 2(A) and (B), respectively. The pure CdS NWs exhibited a nanorod structure with diameters of 40-60 nm and a length of several hundred nanometers. The structures of the
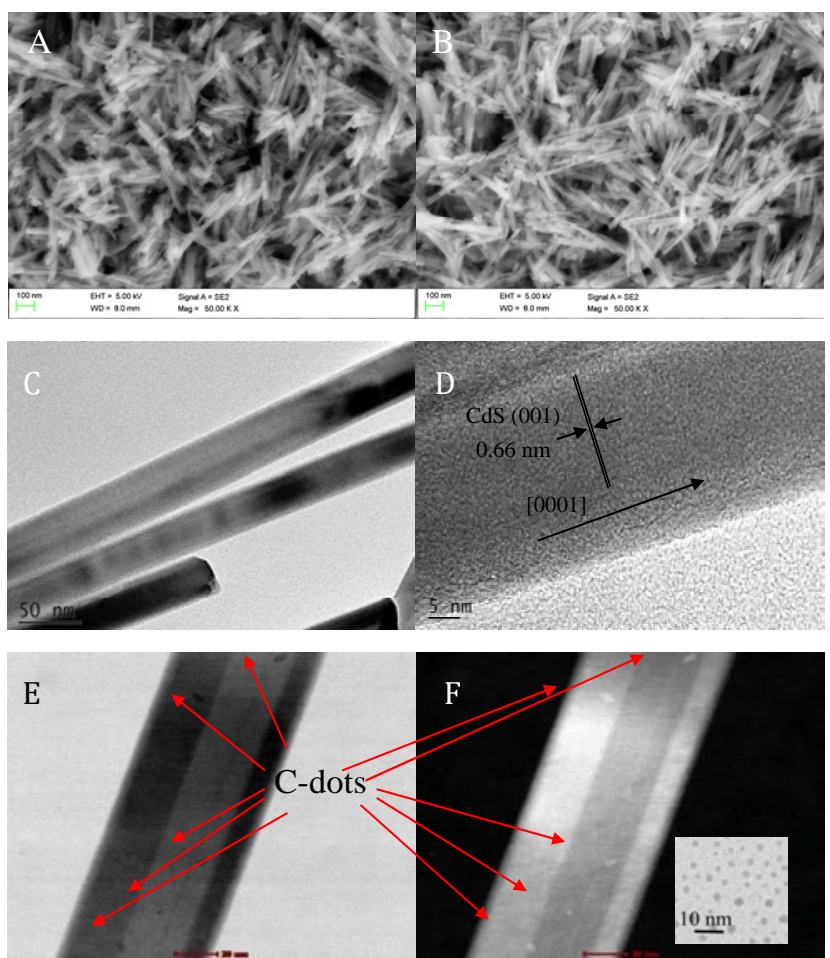

Fig. 2. SEM images of pure CdS NWs (A) and 0.4\% C-dots/CdS NWs (B). TEM images of pure CdS NWs at low (C) and high (D) resolution. TEM (E) and STEM (F) images of $0.4 \%$ C-dots/CdS NWs (inset in Fig. 2(F) shows a TEM image of C-dots) 
CdS NWs within the $0.4 \%$ C-dots/CdS NWs photocatalyst were not affected after modification with the C-dots. A nanorod structure has a large specific surface area when compared with other morphologies and its one-dimensional nanostructure facilitates the rapid transfer of photogenerated carriers to the surface of the catalyst, which can then participate in the photocatalysis reaction [35].

Low- and high-resolution TEM images of pure CdS NWs are shown in Fig. 2(C) and (D), respectively. The diameter of the pure CdS NWs was approximately $50 \mathrm{~nm}$. At higher resolution, the lattice fringes of the pure CdS NWs can be clearly observed, which implied a high level of crystallinity. Lattice widths of 0.66 and $0.36 \mathrm{~nm}$ were observed, which corresponded to the (001) and (100) crystal faces of hexagonal wurtzite CdS, respectively. This result indicated that the CdS NWs grew in the [0001] direction. The surface of the C-dots/CdS NWs was altered, as observed by STEM (Fig. 2(E) and (F)). Furthermore, the TEM image of the C-dots (inset, Fig. 2(F)) exhibited quantum dot structures with particle diameters of 3-5 nm on the surface of the CdS NWs, which indicated the formation of C-dots on the surface of CdS NWs.

The results of XPS studies on the CdS NWs and the $0.4 \%$ C-dots/CdS NWs are shown in Fig. 3. Peaks characteristic of Cd, $\mathrm{S}$ and $\mathrm{C}$ were observed (Fig. 3(A)). High-resolution spectra of Cd $3 d$ (Fig. 3(B)) and S $2 s$ (Fig. 3(C)) indicated that the introduction of the C-dots did not significantly alter the structural properties of CdS, as evidenced by only a very small shift of their characteristic binding energy peaks. High-resolution C $1 s$ spectra of the $0.4 \%$ C-dots/CdS NWs are shown in Fig. 3(D). Peaks were present at 287 and $289.2 \mathrm{eV}$, which corresponded to $\mathrm{C}-\mathrm{O}$ and $\mathrm{C}=\mathrm{O}$ bonds, respectively. Furthermore, the peak

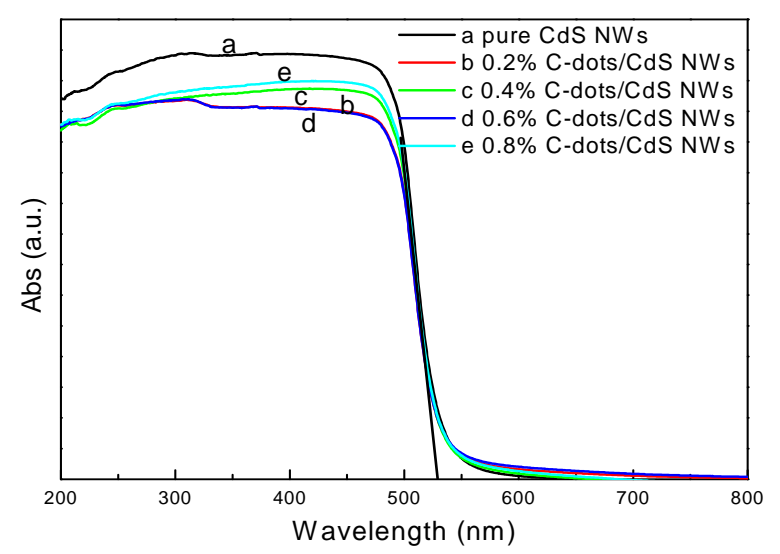

Fig. 4. UV-vis absorption spectra of the CdS NWs and the C-dot/CdS NWs.

observed at $285.2 \mathrm{eV}$ corresponded to a $s p^{2} \mathrm{C}-\mathrm{C}=\mathrm{C}$ bond, which further confirmed that the surface of the CdS NWs was successfully modified with C-dots [36]. Therefore, C-dots/CdS NWs that did not contain impurities were prepared successfully.

UV-vis absorption spectra of the CdS NWs and the C-dot/CdS NWs are shown in Fig. 4. The absorption threshold of pure CdS NWs was approximately $530 \mathrm{~nm}$, which corresponded to a bandgap width of $2.34 \mathrm{eV}$ (using the formula $E_{\mathrm{g}}=$ $1240 / \lambda$ [37]). As the mass fraction of the C-dots increased, the absorption threshold of the CdS NWs did not shift significantly. Throughout the spectral range examined, the light absorption of the samples did not change. This may be because only small amounts of carbon was attached to the surface of the CdS NWs and so did not significantly alter the crystal structure of the CdS.
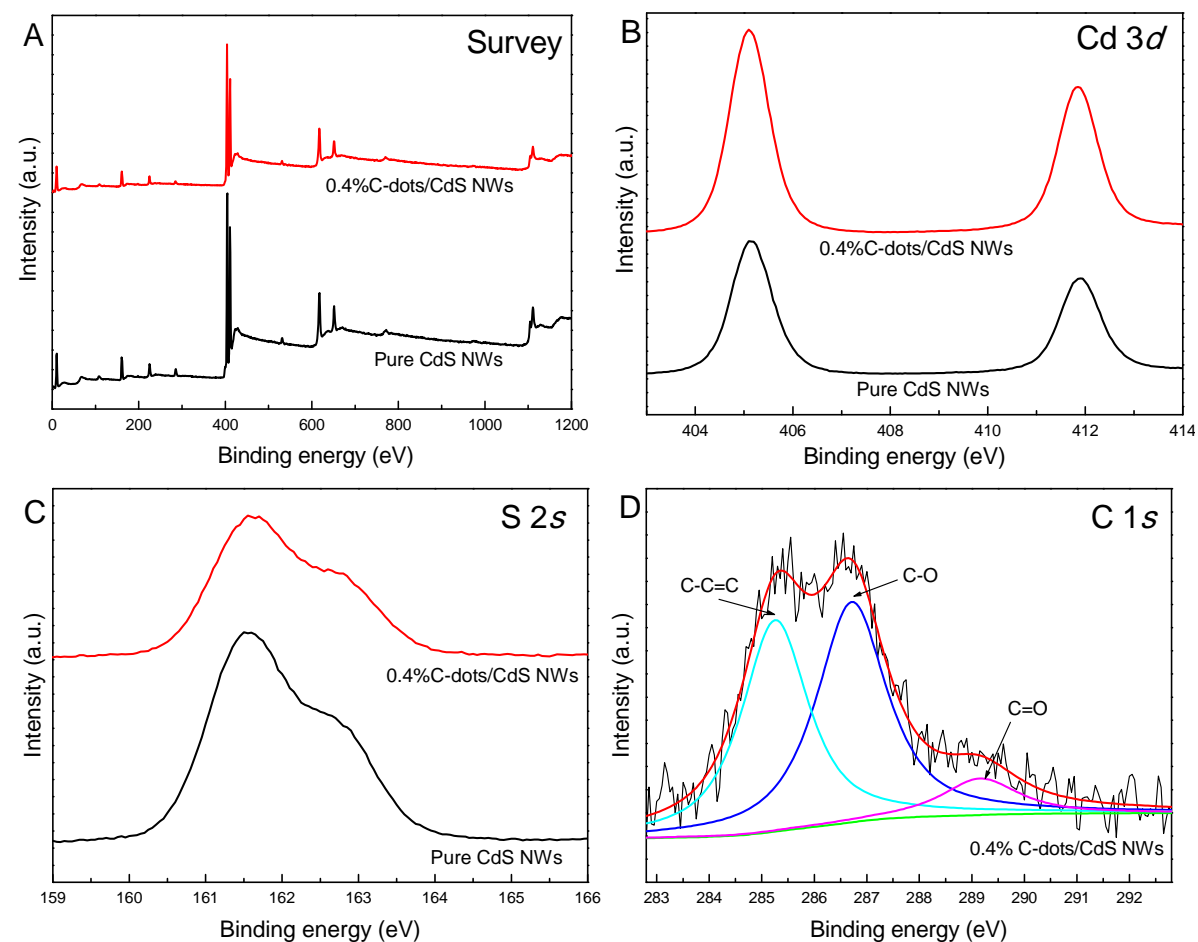

Fig. 3. XPS survey spectra (A) and high-resolution XPS spectra of Cd $3 d$ (B) and S $2 s$ (C) of the CdS NWs and 0.4\% C-dots/CdS NWs. High-resolution XPS spectra of C $1 s$ (D) of the $0.4 \%$ C-dots/CdS NWs. 
The photocatalytic degradation of RhB using the CdS NWs and the C-dot/CdS NWs under visible light irradiation is shown in Fig. 5. Before irradiation, the photocatalyst-dye mixture was stirred in the absence of light for 30 min to reach adsorption equilibrium. As seen in Fig. 5(A), the adsorption of RhB on the C-dots/CdS NWs was slightly higher than that on the pure CdS NWs. The efficiency of the photocatalytic degradation of RhB increased as the mass fraction of the C-dots increased and reached a maximum value at $0.4 \% \mathrm{C}$-dot modification. Approximately $97 \%$ of the $\mathrm{RhB}$ was degraded by the $0.4 \%$ C-dots/CdS NWs after only 60 min of visible light illumination. At higher mass fractions of C-dot modification, the efficiency of the photocatalytic degradation of RhB decreased. The pure CdS NWs only achieved $43 \% \mathrm{RhB}$ degradation after $60 \mathrm{~min}$ of visible light illumination, which rose to approximately $92.5 \%$ after 180 min of visible light illumination as shown in Fig. 5(B).

The kinetic behavior was analyzed (Fig. 5(C)) by transforming the degradation curves shown in Fig. 5(A). The photocatalytic degradation of RhB by the C-dot/CdS NWs exhibited first-order kinetics (rate constants shown in Table 1). The photocatalytic degradation was repeated multiple times to understand the photocatalytic activity and stability of the $0.4 \%$ C-dots/CdS NWs (Fig. 5(D)). After 4 cycles, the degradation of $\mathrm{RhB}$ remained at $95 \%$ after 60 min visible light illumination, which indicated that the C-dots/CdS NWs were not degraded during the photocatalytic reaction.

The degradation of RhB exhibited pseudo-first-order kinetics, which was modeled using $\ln \left(c_{0} / c\right)=k t$, where $c_{0}$ is the initial concentration of RhB, $c$ is the concentration after visible light irradiation, and $k$ is the first order kinetics rate constant (shown in Table 1). The rate constant of the pure CdS NWs
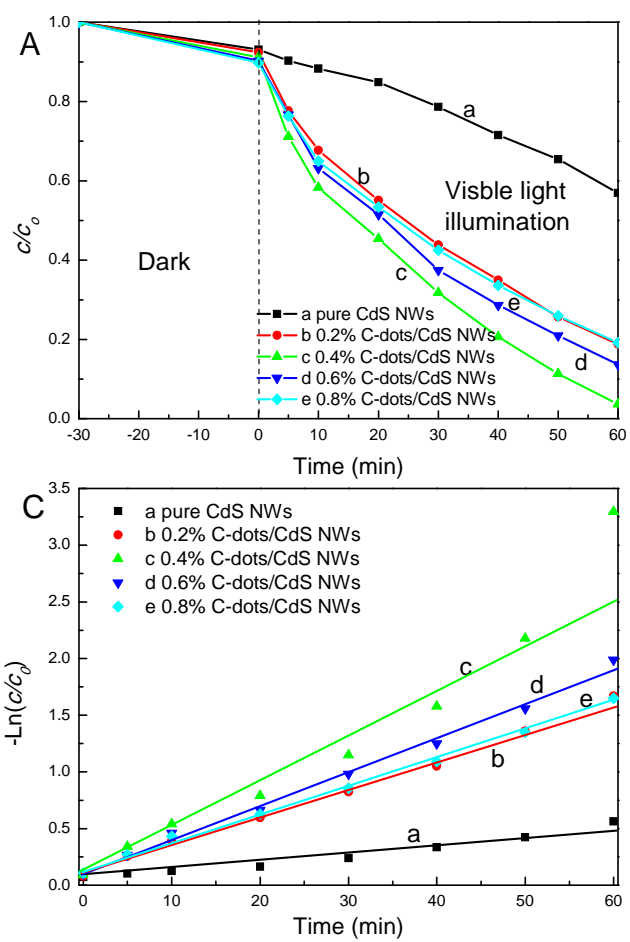

Table 1

Rate constants for the photocatalytic degradation of RhB by pure CdS NWs and the C-dot/CdS NWs.

\begin{tabular}{lc}
\hline Sample & Rate constant $\left(\mathrm{min}^{-1}\right)$ \\
\hline Pure CdS NWs & 0.0084 \\
$0.2 \%$ C-dots/CdS NWs & 0.0260 \\
$0.4 \%$ C-dots/CdS NWs & 0.0484 \\
$0.6 \%$ C-dots/CdS NWs & 0.0309 \\
$0.8 \%$ C-dots/CdS NWs & 0.0255 \\
\hline
\end{tabular}

$\left(0.0084 \mathrm{~min}^{-1}\right)$ improved significantly after modification with the C-dots, with the $0.4 \%$ C-dots/CdS NWs exhibiting the highest rate constant of $0.0484 \mathrm{~min}^{-1}$. The kinetic traces are shown in Fig. 5(C).

The mechanism of the photocatalytic reaction between the C-dots/CdS NWs and RhB was examined by the addition of active radical scavengers, as shown in Fig. 6. IPA and BQ were added as trapping agents for $\cdot \mathrm{OH}$ and $\cdot \mathrm{O}_{2}^{-}$, respectively [38]. Following addition of IPA, the photocatalytic degradation of RhB using the C-dots/CdS NWs was slightly less effective than without the scavengers, which indicated that $\cdot \mathrm{OH}$ was not the primary active product of the degradation process. The degradation of $\mathrm{RhB}$ was inhibited significantly in the presence of $\mathrm{BQ}$, with only $12 \%$ of the RhB being degraded after 60 min of visible light illumination. This result indicated that $\cdot \mathrm{O}_{2^{-}}$played a key role in the photocatalytic degradation process.

The evolution of hydrogen during the photocatalytic splitting of water using CdS NWs and the C-dot/CdS NWs under visible light illumination is shown in Fig. 7. The yield of hydrogen using the C-dots/CdS NWs was substantially higher than that obtained using pure CdS NWs (Fig. 7(A)). A volume histo-
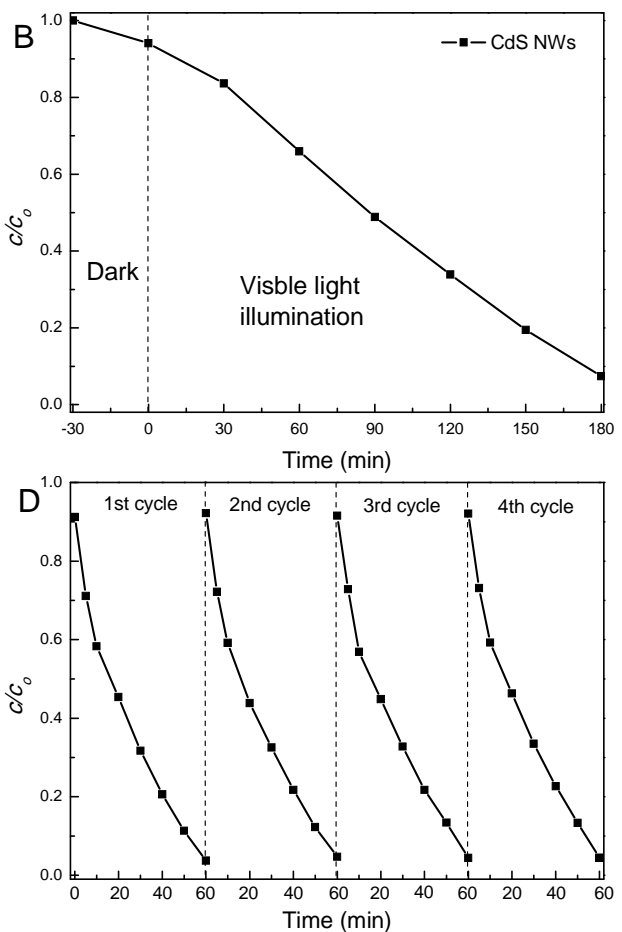

Fig. 5. Photocatalytic degradation of RhB (A, B) by CdS NWs and the C-dot/CdS NWs; The corresponding kinetic curves (C) and cyclic photocatalytic degradation of the $0.4 \%$ C-dots/CdS NWs (D) under visible light irradiation. 


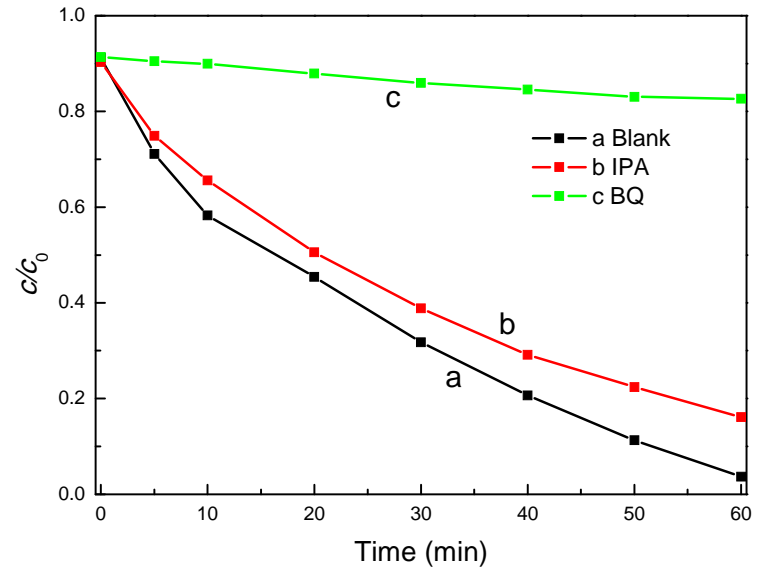

Fig. 6. Photocatalytic degradation of RhB using $0.4 \%$ C-dots/CdS NWs in the absence and presence of free radical traps.

gram showing the hydrogen generation rates is shown in Fig. 7(B). The rate for the photocatalytic evolution of hydrogen using the pure CdS NWs reached $196.9 \mu \mathrm{mol} \mathrm{g}^{-1} \mathrm{~h}^{-1}$. The rates of hydrogen evolution using the C-dots/CdS NWs were enhanced considerably, with the $0.4 \% \mathrm{C}$-dots/CdS NWs exhibiting the highest rate of $1633.9 \mu \mathrm{mol} \mathrm{g}-1 \mathrm{~h}^{-1}$, which was 8.3 times that of pure the CdS NWs. Therefore, the $0.4 \%$ C-dots/CdS NWs had the best photocatalytic performance, which was consistent with the results of photocatalytic degradation of RhB.

$i-t$ curves of the pure CdS NWs and the $0.4 \%$ C-dots/CdS NWs are shown in Fig. 8(A). The photo quantum effect of a semiconductor photocatalyst can be determined indirectly using an $i$ - $t$ curve. The photoinduced current of the $0.4 \%$ C-dots/CdS NWs was significantly larger than that of the pure CdS NWs, which indicated that the $0.4 \%$ C-dots/CdS NWs had a higher photo quantum effect. The photocurrent reduced with increasing time because of reduced interactions between the photocatalysts and FTO under visible light irradiation [39].

The capacity of electrons to migrate in a semiconductor photocatalyst can be characterized using EIS, an so EIS was performed on both pure CdS NWs and the $0.4 \%$ C-dots/CdS NWs (Fig. 8(B)). The resistance arc radius of the $0.4 \%$ C-dots/CdS NWs was much smaller than that of the pure CdS NWs, indicating that the electron mobility of the $0.4 \%$ C-dots/CdS NWs was larger than that of the pure CdS NWs. Thus, the improved photocatalytic performance of the $0.4 \%$ C-dots/CdS NWs was caused by an enhanced separation efficiency of the photogenerated electrons and holes.

PL spectra can give information on the recombination rate of photogenerated electrons and holes in a photocatalyst [40]. The PL intensity of the $0.4 \%$ C-dots/CdS NWs was significantly lower than that of the pure CdS NWs (Fig. 8(C)), indicating that the 0D/1D heterojunction formed within the C-dots/CdS NWs significantly inhibited the recombination of photogenerated carriers and accelerated the separation of the photogenerated electrons and holes. These results showed that the improved photocatalytic performance of the $0.4 \%$ C-dots/CdS NWs was caused by a high photoinduced current, fast electron mobility and a low photogenerated carrier recombination rate.

This work indicated that the 0D C-dots were uniformly distributed on the surface of 1D CdS NWs, which formed a good
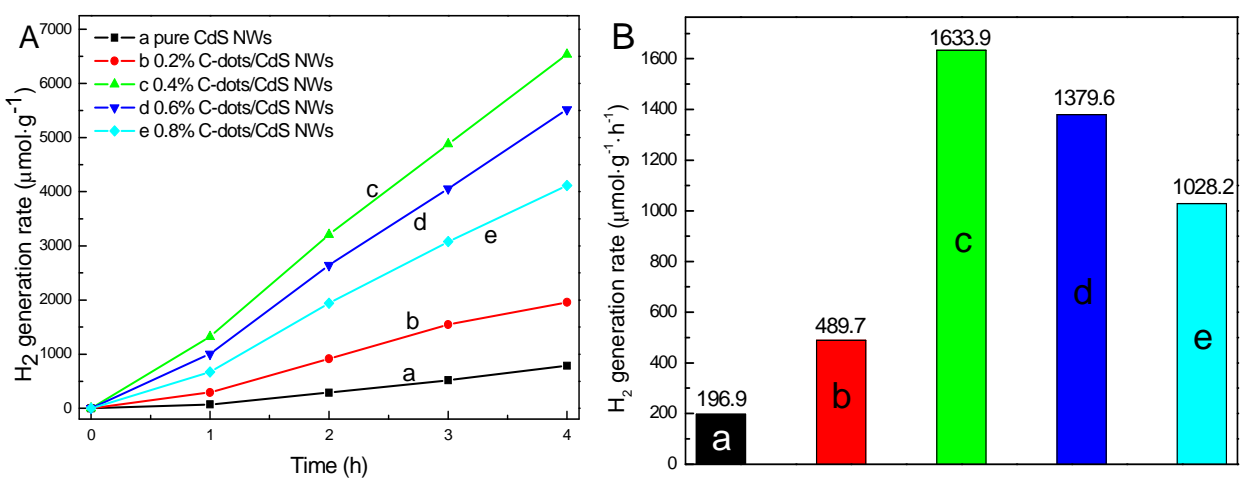

Fig. 7. Rates of hydrogen evolution during the photocatalytic degradation of RhB using pure CdS NWs and C-dot/CdS NWs under visible light illumination. (A) Rate curves; (B) Volume histogram.
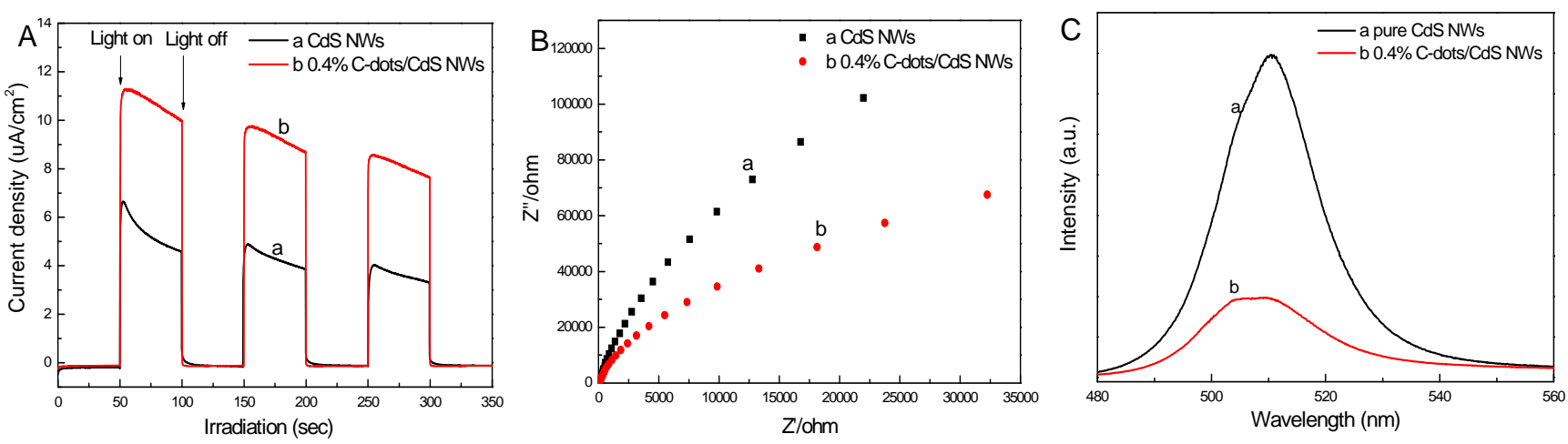

Fig. 8. $i$ - $t$ curves (A), EIS (B) and PL spectra (C) of the pure CdS NWs and $0.4 \%$ C-dots/CdS NWs. 


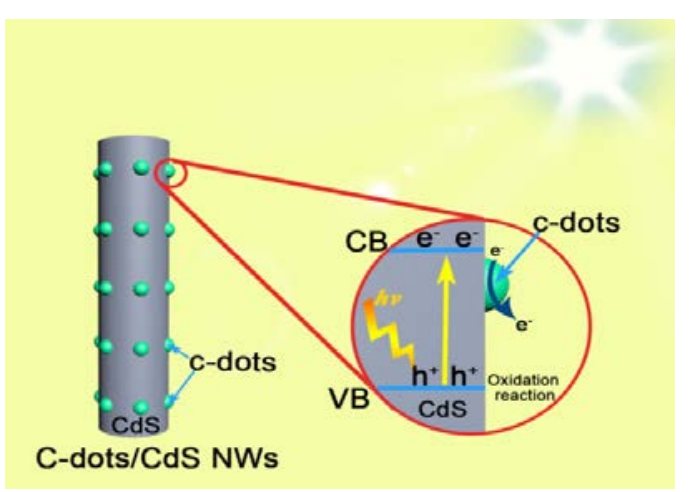

Fig. 9. Schematic showing the photocatalytic mechanism of the C-dots/CdS NWs under visible light illumination.

heterojunction. When the photogenerated electrons were excited to the conduction band (CB) during visible light irradiation, they could transfer rapidly to the surface of the CdS NWs. The C-dots could then act as electron carriers that would accelerate electron transport where they could participation in the photocatalytic reaction. Therefore, the presence of the C-dots enhanced the separation efficiency of the photogenerated electrons and holes, which improved the photocatalytic efficiency.

\section{Conclusions}

We successfully prepared 0D C-dots and 1D CdS NWs by microwave and solvothermal methods, respectively. The C-dots/CdS NWs heterojunction photocatalysts were synthesized using a simple chemical deposition method. Physical characterization revealed that the surface of the CdS NWs was successfully modified with the C-dots, which resulted in the formation of a good heterojunction structure. The as-prepared C-dots/CdS NWs exhibited improved photocatalytic performance when compared with the pure CdS NWs, with the $0.4 \%$ C-dots/CdS NWs showing the best photocatalytic activity. The C-dots/CdS NWs generated a higher photoinduced current, a faster rate of electron transmission and a higher separation efficiency of photogenerated electron-hole pairs, which significantly enhanced the photocatalytic performance of the C-dots/CdS NWs.

\section{References}

[1] K. Maeda, K. Teramura, D. L. Lu, T. Takata, N. Saito, Y. Inoue, K. Domen, Nature, 2006, 440, 295.

[2] H. Du, Y. N. Liu, C. C. Shen, A. W. Xu, Chin. J. Catal., 2017, 38, 1295-1306.

[3] A. Fujishima, K. Honda, Nature, 1972, 238, 37-38.

[4] I. Paramasivam, H. Jha, N. Liu, P. Schmuki, Small, 2012, 8, 3073-3103.

[5] C. Z. Luo, X. H. Ren, Z. G. Dai, Y. P. Zhang, X. Qi, C. X. Pan, ACS Appl. Mater. Interfaces, 2017, 9, 23265-23286.

[6] S. G. Kumar, L. G. Devi, J. Phys. Chem. A, 2011, 115, 13211-13241.

[7] I. Majeed, M. A. Nadeem, M. Al-Oufi, M. A. Nadeem, G. I. N. Waterhouse, A. Badshah, J. B. Metson, H. Idriss, Appl. Catal. B, 2016, 182, 266-276.

[8] Z. R. Tang, B. Han, C. Han, Y. J. Xu, J. Mater. Chem. A, 2017, 5, 2387-2410.

[9] S. Farhadi, F. Siadatnasab, Chin. J. Catal., 2016, 37, 1487-1495.

[10] J. Z. Su, T. Zhang, L. Wang, J. W. Shi, Y. B. Chen, Chin. J. Catal., 2017, $38,489-497$.

[11] D. M. Chen, Q. Hao, Z. H. Wang, H. Ding, Y. F. Zhu, CrystEngComm, 2016, 18, 1976-1986.

[12] Z. J. Ning, H. N. Tian, H. Y. Qin, Q. Zhang, H. Agren, L. C. Sun, Y. Fu, J. Phys. Chem. C, 2010, 114, 15184-15189.

[13] J. Liu, Y. Liu, N. Y. Liu, Y. Z. Han, X. Zhang, H. Huang, Y. Lifshitz, S. T. Lee, J. Zhong, Z. H. Kang, Science, 2015, 347, 970-974.

[14] H. Q. Cao, Y. Xu, J. M. Hong, H. B. Liu, G. Yin, B. L. Li, C. Y. Tie, Z. Xu, Adv. Mater., 2001, 13, 1393-1394.

[15] Y. X. Yin, Z. G. Jin, F. Hou, Nanotechnology, 2007, 18, 495608/1495608/6.

[16] X. F. Gao, W. T. Sun, Z. D. Hu, G. Ai, Y. L. Zhang, S. Feng, F. Li, L. M. Peng, J. Phys. Chem. C, 2009, 113, 20481-20485.

[17] G. R. Yang, W. Yan, Q. Zhang, S. H. Shen, S. J. Ding, Nanoscale, 2013, 5, 12432-12439.

[18] Y. Y. Bu, Z. Y. Chen, W. B. Li, J. Q. Yu, ACS Appl. Mater. Interfaces, 2013, 5, 5097-5104.

[19] X. L. Yin, L. L. Li, W. J. Jiang, Y. Zhang, X. Zhang, L. J. Wan, J. S. Hu, ACS Appl. Mater. Interfaces, 2016, 8, 15258-15266.

[20] H. W. Zhang, S. Delikanli, Y. L. Qin, S. L. He, M. Swihart, H. Zeng, Nano Res., 2008, 1, 314-320.

[21] K. P. Xie, Q. Wu, Y. Y. Wang, W. X. Guo, M. Y. Wang, L. Sun, C. J. Lin, Electrochem. Commun., 2011, 13, 1469-1472.

[22] Q. Hao, R. T. Wang, H. J. Lu, C. A. Xie, W. H. Ao, D. M. Chen, C. Ma, W. Q. Yao, Y. F. Zhu, Appl. Catal. B, 2017, 219, 63-72.

\section{Graphical Abstract}

\section{Chin. J. Catal., 2018, 39: 841-848 doi: 10.1016/S1872-2067(17)62972-3}

\section{Enhanced visible-light-driven photocatalytic activities of 0D/1D heterojunction carbon quantum dot modified CdS nanowires}

Zhiwei Chen, Chang Feng *, Weibing Li *, Zhiyong Sun, Jian Hou,

Xiangbo Li, Likun Xu, Mingxian Sun, Yuyu Bu*

Qingdao University of Science and Technology;

Luoyang Ship Material Research Institute; Xidian University

0D/1D heterojunction of C-dots/CdS NWs was prepared to investigate the enhanced photocatalytic performance under visible light irradiation. The heterojunction establishment can effectively improve the electronic transmission capacity, and promote the separation efficiency of photogenerated carriers of C-dots/CdS NWs.

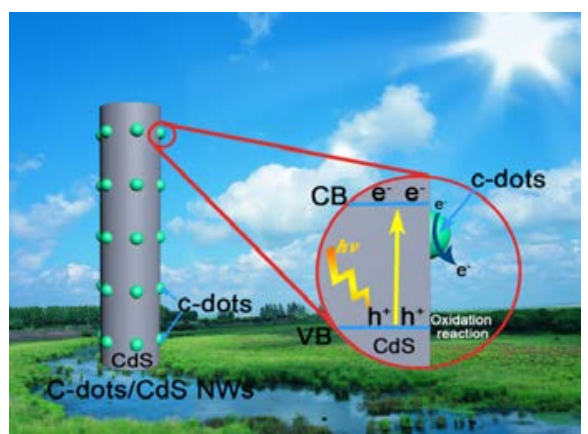


[23] Q. Hao, S. M. Hao, X. X. Niu, X. Li, D. M. Chen, H. Ding, Chin. J. Catal., 2017, 38, 278-286.

[24] B. Weng, S. Q. Liu, N. Zhang, Z. R. Tang, Y. J. Xu, J. Catal., 2014, 309, 146-155.

[25] K. Q. Lu, Q. Quan, N. Zhang, Y. J. Xu, J. Energy Chem., 2016, 25, 927-935.

[26] X. Y. Xu, R. Robert, Y. L. Gu, H. J. Ploehn, L. Gearheart, K. Raker, W. A. Scrivens, J. Am. Chem. Soc., 2004, 126, 12736-12737.

[27] H. C. Zhang, H. Huang, H. Ming, H. T. Li, L. L. Zhang, Y. Liu, Z. H. Kang, J. Mater. Chem., 2012, 22, 10501-10506.

[28] C. Ampelli, S. Perathoner, G. Centi, Chin. J. Catal., 2014, 35, 783-791.

[29] P. Chen, F. L. Wang, Z. F. Chen, Q. X. Zhang, Y. H. Su, L. Z. Shen, K. Yao, Y. Liu, Z. W. Cai, W. Y. Lv, G. G. Liu, Appl. Catal. B, 2017, 204, 250-259.

[30] H. Zhang, L. X. Zhao, F. L. Geng, L. H. Guo, B. Wan, Y. Yang, Appl. Catal. B, 2016, 180, 656-662.

[31] H. J. Yu, R. Shi, Y. F. Zhao, G. I. N.Waterhouse, L. Z. Wu, C. H. Tung, T. R. Zhang, Adv. Mater., 2016, 28, 9454-9477.
[32] X. Zhang, F. Wang, H. Huang, H. T. Li, X. Han, Y. Liu, Z. H. Kang, Nanoscale, 2013, 5, 2274-2278.

[33] J. X. Xia, J. Di, H. T. Li, H. Xu, H. M. Li, S. J. Guo, Appl. Catal. B, 2016, $181,260-269$.

[34] Y. Huang, Y. L. Liang, Y. F. Rao, D. D. Zhu, J. J. Cao, Z. X. Shen, W. K. Ho, S. C. Lee, Environ. Sci. Technol., 2017, 51, 2924-2933.

[35] B. Han, S. Q. Liu, N. Zhang, Y. J. Xu, Z. R. Tang, Appl. Catal. B, 2017, 202, 298-304.

[36] C. Feng, X. Y. Deng, X. X. Ni, W. B. Li, Acta Phys.-Chim. Sin., 2015, 31, 2349-2357.

[37] A. Tsuge, Y. Uwamino, T. Ishizuka, K. Suzuki, Appl. Spectrosc., 1991, 45, 1377-1380.

[38] W. B. Li, Y. P. Zhang, Y. Y. Bu, Z. Y. Chen, J. Alloys Compd., 2016, 680, 677-684.

[39] Q. Hao, X. X. Niu, C. S. Nie, S. M. Hao, W. Zou, J. M. Ge, D. M. Chen, W. Q. Yao, Phys. Chem. Chem. Phys., 2016, 18, 31410-31418.

[40] L. Q. Jing, Y. C. Qu, B. Q. Wang, S. D. Li, B. J. Jiang, L. B. Yang, W. Fu, H. G. Fu, J. Z. Sun, Sol. Energy Mater. Sol. Cells, 2006, 90, 1773-1787.

\title{
0D/1D碳点修饰硫化镉纳米线异质结增强可见光光催化性能
}

\author{
陈治伟 ${ }^{\mathrm{a}, \mathrm{b}}$, 冯 昌 ${ }^{\mathrm{b}, *}$, 李卫兵 ${ }^{\mathrm{a}, \mathrm{b}, \# \text {, 孙智勇 }}{ }^{\mathrm{b}}$, 侯 建 $^{\mathrm{b}}$, 李相波 ${ }^{\mathrm{b}}$, 许立坤 ${ }^{\mathrm{b}}$, 孙明先 ${ }^{\mathrm{b}}$, 补钰显, ${ }^{\mathrm{c} \$}$ \\ a青岛科技大学环境与安全工程学院, 山东青岛 266042 \\ b 中国船舶重工集团公司第七二五研究所海洋腐蚀与防护重点实验室, 山东青岛 266237 \\ `西安电子科技大学微电子学院宽禁带半导体材料与器件国家重点实验室, 陕西西安710071
}

摘要: 硫化镉(CdS)作为一种对可见光响应的窄带隙半导体(带隙宽度约为 $2.4 \mathrm{eV}$ ), 具有合适的能带位置, 近年来受到越来 越多的重视. 然而在光催化过程中, 光生电子与空穴的快速复合极大地限制了CdS的实际应用, 如何提高光生电子-空穴对 的分离效率成为研究重点. 一维CdS纳米棒(1D CdS NWs) 具有较大的长径比, 能快速有效地转移光生载流子. 零维碳点 (0D C-dots) 是一种粒径在 $10 \mathrm{~nm}$ 以下的新型纳米碳材料, 其作为助催化剂能够加快光生载流子传递速率, 可提高材料光催 化性能. 因此, 通过C-dots对CdS NWs进行修饰并形成异质结, 利用C-dots助催化剂的作用以提升CdS NWs的光催化性能, 具有一定的可行性.

本文成功构建了一种 $0 \mathrm{D} / 1 \mathrm{D}$ 碳点修饰CdS NWs 异质结(C-dots/CdS NWs), 并考察其光催化性能. 通过X射线衍射 (XRD)、扫描电子显微镜(SEM)、透射电子显微镜(TEM)、X射线光电子能谱(XPS)和紫外-可见(UV-Vis)吸收光谱等技术对 系列C-dots/CdS NWs样品进行表征. 研究发现, C-dots成功负载在CdS NWs的表面并形成异质结. 通过测试系列样品在可 见光照射下光催化降解罗丹明B (RhB) 以及光催化产氢性能发现, C-dots的修饰能够有效增强CdS NWs的光催化性能, 其中 $0.4 \%$ C-dots/CdS NWs 表现出最佳的光催化降解RhB活性, 其经可见光照射 60 min即可实现对RhB的完全降解(相同条件下 CdS NWs需要 $180 \mathrm{~min}$ ). 同时自由基捕获实验表明, $\cdot \mathrm{O}_{2}{ }^{-}$是降解罗丹明 $\mathrm{B}$ 过程中的主要活性基团. 在光催化产氢性能测试中, $0.4 \%$ C-dots/CdS NWs样品表现出最高的光催化产氢能力, 产氢速率可达 $1633.9 \mu \mathrm{mol} \mathrm{g}^{-1} \mathrm{~h}^{-1}$, 比纯CdS的 $\left(196.9 \mu \mathrm{mol} \mathrm{g}^{-1} \mathrm{~h}^{-1}\right)$ 提高了 8.3倍, 并且C-dots/CdS NWs具有良好的稳定性. 研究发现, 在可见光照射下, C-dots/CdS NWs能够产生较强的光生 电流, 且形成的0D/1D C-dots/CdS NWs 异质结具有良好的电子传输能力, 实现了C-dots/CdS NWs光生电子与空穴的有效分 离, 从而增强了光催化性能.

关键词: 半导体光催化; 异质结; CdS纳米线; 碳量子点; 水分解

收稿日期: 2017-11-19. 接受日期: 2017-12-09. 出版日期: 2018-04-05.

*通讯联系人. 电话: (0532)68725125; 传真: (0532)68725100; 电子信箱: fchang1988@126.com

\#通讯联系人. 电话/传真: (0532)84022617; 电子信箱: Iwbing@qust.edu.cn

\$通讯联系人. 电话/传真: (029)88202505; 电子信箱: buyuyuqust@163.com

基金来源：洛阳船船材料研究所(LSMRI)海洋腐蚀与防护国家重点实验室开放基金(KF160413); 国家自然科学基金(21301161, 41376126).

本文的电子版全文由Elsevier出版社在ScienceDirect上出版(http://www.sciencedirect.com/science/journal/18722067). 